\title{
Effectiveness of Mindfulness Based Stress Reduction Therapy Among Parents of Children with Autism Spectrum Disorder
}

\section{Pravina Govindasamy, Aizan Sofia Amin \& Nasrudin Subhi}

To Link this Article: http://dx.doi.org/10.6007/IJARBSS/v12-i1/12097

DOI:10.6007/IJARBSS/v12-i1/12097

Received: 08 November 2021, Revised: 12 December 2021, Accepted: 27 December 2021

Published Online: 19 January 2022

In-Text Citation: (Govindasamy et al., 2022)

To Cite this Article: Govindasamy, P., Amin, A. S., \& Subhi, N. (2022). Effectiveness of Mindfulness Based Stress Reduction Therapy Among Parents of Children with Autism Spectrum Disorder. International Journal of Academic Research in Business and Social Sciences, 12(1), 779-792.

Copyright: (c) 2022 The Author(s)

Published by Human Resource Management Academic Research Society (www.hrmars.com)

This article is published under the Creative Commons Attribution (CC BY 4.0) license. Anyone may reproduce, distribute, translate and create derivative works of this article (for both commercial and non0-commercial purposes), subject to full attribution to the original publication and authors. The full terms of this license may be seen at: http://creativecommons.org/licences/by/4.0/legalcode

Vol. 12, No. 1, 2022, Pg. $779-792$

Full Terms \& Conditions of access and use can be found at http://hrmars.com/index.php/pages/detail/publication-ethics 


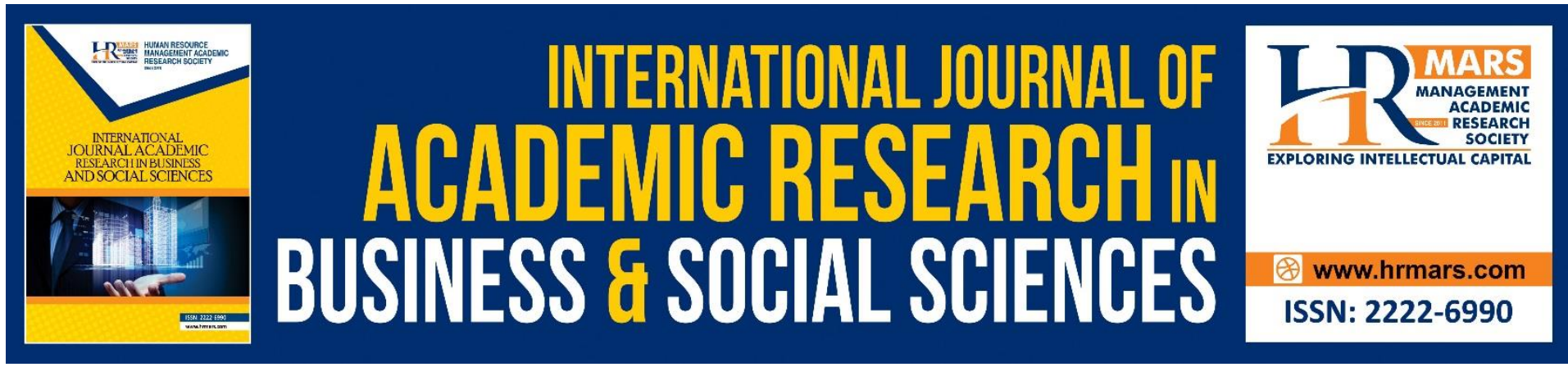

\title{
Effectiveness of Mindfulness Based Stress Reduction Therapy Among Parents of Children with Autism Spectrum Disorder
}

\author{
Pravina Govindasamy, Aizan Sofia Amin \& Nasrudin Subhi \\ Center for Research in Psychology and Human Well-Being, Faculty of Social Science and \\ Humanities, Universiti Kebangsaan Malaysia, 43600 Bangi, Selangor, Malaysia \\ Corresponding Email: aizansofia@ukm.edu.my
}

\begin{abstract}
Past research in the Autism Spectrum Disorder (ASD) field has raised concerns about the effectiveness of Mindfulness Based Stress Reduction (MBSR) therapy as a parent-focused intervention. A better understanding of the efficacy of this intervention can inform clinicians and policymakers and lead to improved outcomes for both parents and children. This systematic review aimed to examine studies measuring the effectiveness of MBSR intervention among parents of children with ASD (>2.5 yr) and investigate its outcome on parent-child mental health and wellbeing. An electronic database search was conducted using Scopus, Web of Science, Springer and Science Direct. This review indicated that MBSR plays a vital role as a proven intervention in improving parents' mental health, mainly on parental stress, mindfulness, anxiety, depression, child behaviour and life satisfaction. At the same time, MBSR has indirect positive effects on the ASD child's behaviour and mental health. This review verified previous studies on the outcome of MBSR therapy among parents of children with ASD and highlighted potential support areas. Implications for future research, policy and practice are also discussed in this paper.
\end{abstract}

Keyword: Mindfulness, Mindfulness Based Stress Reduction Therapy, Autism Spectrum Disorder, Children, Parents.

\section{Introduction}

The institution of the family is an important unit in societal life and parents play a very important role in building a healthy family. Raising a child is one of the important tasks in this couple's life. However, this journey becomes more difficult when their child shows symptoms or is diagnosed with a developmental disorder, such as Autism Spectrum Disorder (ASD) (Zarbo et al., 2016). ASD is known to be a complex neurocognitive syndrome disrupting the functioning of daily life specifically in aspects of interaction and social engagement for a long period of time (Drmic, et al., 2018). This condition directly causes individuals with ASD, continue to struggle to adapt to the social world and have to seek help from mental health professionals (Help 2016). 
According to the American Psychiatric Association [APA] (2013), this syndrome is determined when there is persistent disruption in social interaction and communication abilities whether verbal or nonverbal as well as limited or repetitive behaviours, interests, or activities. The symptoms of this disorder are very difficult to predict (Kord \& Bazzazian, 2020) and this causes ASD to be seen as a complex disorder that lasts a lifetime, as well as having a negative impact on self and family (Karst \& Van Hecke, 2012). While existing therapies focus more on skill acquisition and behaviour change as well as the rehabilitation of individuals with ASD, but the well-being of parents is out of sight even though they are also a high-risk population. (Millstein et al., 2020).

The experience of raising a child with ASD is certainly stressful for parents (Zarbo et al., 2016), impairing their functioning as parents thus leading to poor self-efficacy in themselves (Brockman et al., 2015). Furthermore, a local study by Siah and Tan (2016) emphasized that parents of children with ASD are more likely to have a negative impact on family functioning and lead to a low quality of life while they are also challenged to allocate time and pay attention to other children and this challenge leads to the notion that they fail to carry out responsibilities and act as good parents (Ilias et al., 2019). Numerous studies have conducted on wellbeing of this population and reported parents of children with ASD are being reported to be having elevated stress level (Dabrowska \& Pisula, 2010; Hayes \& Watson, 2013; Dumas et al., 1991), poorer quality of life (Vasilopoulou \& Nisbet, 2016) marital disfunction (Hartley, 2012) and financial constraint (Kamaralzaman et al., 2018).

Furthermore, parents of children with ASD must face stigma from society due to the complexity of ASD symptoms such as aggressive or passive behaviour and this causes the community and other family members fail to understand ASD syndrome thus forming prejudices about the behaviour of children with ASD (Ilias et al., 2019; Lindly et al., 2016). To address this phenomenon, a psychology-based service is needed to help parents of children with ASD overcome psychological problems and understand the issues and challenges faced by the disabled. Intervention that promotes mindfulness as the core feature found to assist parents of ASD on improving their mental health (Dykens et al., 2014; Neece, 2013; Pisula \& Anna, 2017; Dardas \& Ahmad, 2013). According to Kabat Zinn (2003) mindfulness is being refers to an application of paying attention or focusing in a particular way that requires the individual to focus on the current moment, with full intention, without judging anyone and with compassion.

Mindfulness teaches awareness to parents of children with ASD and to be non-judgemental which finally allows these parents to manage their negative reactions that arise when caring for the needs of children with disabilities independently (KabatZinn, 2003). So far, mindfulness-based interventions have been delivered to diverse groups, including person with ASD as well as to their families, teachers and caretakers (Cachia et al., 2015). A there is a growing interest in this research line since data gathered from mindfulness based interevention are helpful for many practicioners to implement in their field work. On the other hand, many research focus on the impact and factors of parental stress, quality of life, and also child behaviour outcome within parents of ASD children (Cachia et al., 2015; Osborn et al., 2021; Neece et al., 2018; Kuhlthau et al., 2014). Among many mindfulness - based therapies that has been introduced and tested scientifically, Mindfulness Based Stress Reduction (MBSR) found to be effective in assisting parents with ASD children on improving 
their overall well being. MBSR pioneered by Kabat-Zinn describes the role of mindfulness and awareness in improving parental conditions and the same time treating their children with external behavioral problems, a disruptive disorder faced by children with ASD.

\section{Towards a Systematic Review Framework on MBSR Interventions}

A systematic review is an examination of a clearly formulated question that uses systematic and explicit methods to identify, select and critically appraise relevant research and to collect and analyse data from studies that are included in the review (Liberati et al., 2009). Using this approach, researcher carried out a rigorous search on existing databases allowing the identification of the gaps and needed directions for future research. Despite its growing evidence-base, the effectiveness of MBSR therapy on parents of children with ASD remains to be reported. This article attempts to fill the gap in understanding, and identifies and characterizes the MBSR therapy outcome among parents of children with ASD. Reports on outcome in the peer reviewed literature are used as a proxy of outcome, underscoring that this study provides a general and baseline overview of outcome in the region. The work fills an important gap in the literature, with most systematic review examining the outcome of Mindfulness Based therapy as holistic approach and not focused on MBSR, or focused on bigger populations such as other developmental disabilities such as ADHD and physical disabilities.

This study is important as so far there are lack of studies that provide a holistic baseline on the MBSR focused intervention and its outcome on parents of children with ASD. Prior to this study, systematic review articles are only available for overall mindfulness approach for this targeted population hence the outcome of MBSR alone is not being captured in any of the review articles. On the other hand, this study will comprehend the latest trending of MBSR and its outcome as similar systematic review study had covered till the year of 2014 which is 8 years backdated (Cachia et al., 2015). This study had implemented a proper search (e.g., databases searched, articles excluded, search terms used) which eventually make it easy for future scholars to replicate the study, validate the interpretation, or examine the comprehensiveness.

Therefore this study will focus to review the existing literature where MBSR interventions are applied to parents of children with ASD to address their wellbeing and mental health issues. For this purpose, a methodological approach based on a systematic literature review is proposed, which provides an overview of the current state of research, as well as presents the challenges and future research directions. The main focus of the study is the outcome of the MBSR interventions focusing on parental wellbeing and mental health status. A special focus on family and also the diagnosed child outcome of the MBSR intervention while being applied to the parents are also being reported through this research. This section explains the purpose of conducting a systematic review while the second section details out the methodology section and the PRISMA Statement (Preferred Reporting Items Systematic Reviews and Meta-Analysis) approach used. The third section systematically reviews and synthesizes the scientific literature to identify, select and appraise relevant research on MBSR therapies among the parents and children with ASD. The last section identifies future research priorities. 


\section{Method}

The systematic review of this research target parent-focused MBSR interventions documented and compared the impacts and encompassing outcomes that relate to the parents and their ASD child. This section explains the main sub-sections, namely research questions, PRISMA, resources, inclusion and exclusion criteria, systematic review process and data extraction and analysis which are employed in the current research (Liberati et al. 2009).

\section{Research Questions}

Before the review being carried forward, it is necessary to draft a clear and concise research questions which will drive the entire systematic review methodology. As the objectives of this article are; to analyze the outcome of MBSR therapy among parents of children with ASD, the following questions have been selected:

- Q1. What are the studies characteristics?

- Q2. What are the intervention outcomes to the parents and children ?

\section{PRISMA}

PRISMA or Preferred Reporting Items for Systematic Reviews is a standard guideline for researchers to conduct a systematic literature review. Generally, publication standards are required to guide authors with the related and necessary information that will enable them to produce full search strategy for at least one major database (Liberati et al., 2009). PRISMA examines the extensive database of scientific literature at a defined time which allows an systematic search of keywords to be conducted in regard to this research focus which is the effectiveness of MBSR therapy within parents of ASD children.

\section{Resources}

The current study implements the systematic literature review method using two major databases, namely Scopus and Web of Science considering these both databases are high quality indexed journals. Specifically, Scopus has added over 160 million cited references to its database recently, while Web of Science indexes a number of 374,326 cited references particularly in social science studies. However, it should be noted that no database is perfect or comprehensive including Scopus and Web of Science (Shaffril et al. 2019) therefore in the effort of making a rigorous search, the author extended manual searching process to other established sources such as Springer and Taylor \& Francis.

\section{The Systematic Review Process for Selecting the Articles}

The systematic review process in selecting a number of relevant articles for the present study consisted of four main stages, which are identification, screening, eligibility and inclusion.

\section{i) Identification}

The first stage is the identification of keywords or terms followed by the process of searching for related and similar terms based on the thesaurus, dictionaries, encyclopedia, and past researches. Accordingly, search strings on Scopus and Web of Science database were developed (Refer Table 1) after all relevant keywords managed to be determined. Most importantly, the current research work successfully retrieved a total of articles from both databases. As previously stated, manual searching based on similar keywords was conducted on other databases which resulted in an additional number of 51 articles. In total, 447 articles 
were retrieved in the first stage of the systematic review process. At this stage, after careful screening, 111 duplicated articles were removed.

Table 1 - Keywords and Searching Information Strategy Example

\begin{tabular}{|c|c|}
\hline Databases & Keywords used \\
\hline Scopus & $\begin{array}{l}\text { TITLE-ABS-KEY ( ( "disabl*" OR "autis*" OR "ASD" OR "special need*" } \\
\text { OR "Autism Spectrum Disorder*" OR "Asperger's" OR "Pervasive } \\
\text { Developmental Disorder") AND ("parent*" OR "family" OR } \\
\text { "caregiver*" OR "mother" OR "father") AND ("Mindf*" } \\
\text { "meditation")) }\end{array}$ \\
\hline Web of Science & $\begin{array}{l}\text { TS = ( "disabl*" OR "autis*" OR "ASD" OR "special need*" OR "Autism } \\
\text { Spectrum Disorder*" OR "Asperger's" OR "Pervasive Developmental } \\
\text { Disorder" ) AND ( "parent*" OR "family" OR "caregiver*" OR "mother" } \\
\text { OR "father") AND ( "Mindf*" OR "meditation" ) ) }\end{array}$ \\
\hline
\end{tabular}

\section{ii) Screening}

The second stage was screening. The author assessed the retained studies by examining the full-text to determine eligibility and inclusion. At this stage, out of 336 articles eligible to be reviewed, a total of 259 articles were removed.

Table 2: The inclusion and exclusion criteria

\begin{tabular}{|l|l|l|}
\hline Criterion & Eligibility & Exclusion \\
\hline Type of Study & Quantitative & Qualitative \\
\hline Literature type & Journal (research articles) & $\begin{array}{l}\text { Journals (systematic review), book } \\
\text { series, book, chapter in book, } \\
\text { conference proceeding }\end{array}$ \\
\hline Language & English & Non-English \\
\hline Timeline & Between 2005-2021 & $<2005$ \\
\hline $\begin{array}{l}\text { Target } \\
\text { Intervention }\end{array}$ & MBSR & $\begin{array}{l}\text { Other mindfulness therapies such as } \\
\text { MYMind, Mindfulness Based } \\
\text { Program, MBPBS }\end{array}$ \\
\hline Study Aim & $\begin{array}{l}\text { Measuring effectiveness of } \\
\text { therapy }\end{array}$ & $\begin{array}{l}\text { Comparison articles, } \\
\text { Nonexperimental approach }\end{array}$ \\
\hline Population & Parents of children with ASD & $\begin{array}{l}\text { Other than parents of children with } \\
\text { ASD such as caretaker, grandparents, } \\
\text { teachers. }\end{array}$ \\
\hline
\end{tabular}

\section{iii) Eligibility}

The third stage is eligibility, where the a total of 77 full articles were accessed. After careful examination, a total of 69 articles were excluded as some did not focus on parents of children with ASD, were not empirical articles or did not focus outcome of MBSR therapy. At this stage articles that not having MBSR as their core program or using MBSR approach to create custom made mindfulness based program have been removed. While ASD is one of developmental disability category, the size sample of each studies carefully accessed. Parents of children with ASD sample size should represent minumum $60 \%$ from the developmental disabilities category are acceptable as its indicates majority of the parents in the sample are parents of children with ASD. 
iv) Inclusion

The last stage of review resulted in a total of 8 articles that were used for the analysis (see Fig. 1). The following data were extracted from each study by the author which comprises the study characteristics (e.g., no of participation, location), sample characteristics (e.g., parent and child age, type of ASD, ASD severity), characteristics of the MBSR (e.g., framework, duration, delivery), outcome measure used and statitical analysis of each studies.

\section{Data Abstraction and Analysis}

The remaining articles were assessed and analysed. Efforts were concentrated on specific studies that responded to the formulated questions. The data were extracted by reading through the abstracts first, then the full articles (in-depth) to identify appropriate information needed for analysis.
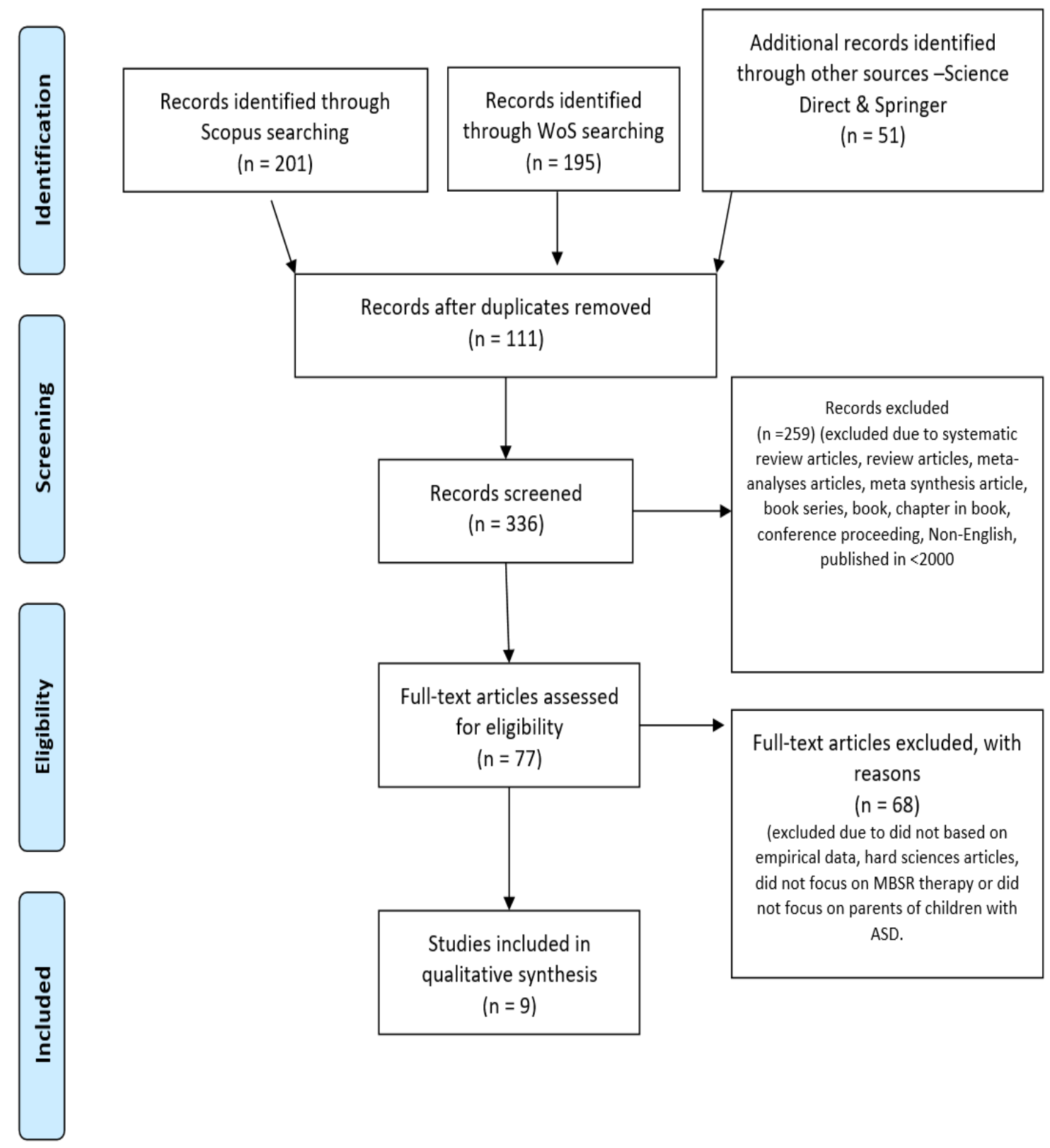

$$
(n=9)
$$

Fig. 1 PRISMA flow diagram of study selection process (Liberati et al. 2009) 


\section{Result}

Data Synthesis

A systematic qualitative synthesis was used to summarise the characteristics and findings of the reviewed studies. Findings are synthesised in order by research question. To answer the first two research questions, studies which focus on MBSR therapy effectiveness of parents of children with ASD to a waitlisting or control group of parents of typically developing children or to population norms are presented.

\section{Research Question 1: Participants and Settings}

The reviewed studies collectively involved 408 parents of children with ASD. The parent's age at the time of the study ranged from 23 to 76 years. Six studies stated the participants employment status, with $54.2 \%$ of the participants being on paid employment $(n=608)$. Children in the reviewed studies had a range of ASD diagnoses, including Autism or Autistic Disorder, Asperger's Syndrome (AS) and PDD-NOS and also being grouped as developmental disability. The age of children with ASD ranged from 0 to 10 years except one study include adults with ASD with the age range of 2-54yr (Dykens et al. 2014). The study characteristics based on previous studies are presented in Table 1. 
Table 1 Study Characteristics of MBSR intervention among parents of children with ASD

\begin{tabular}{|c|c|c|c|c|c|c|c|}
\hline Author & Design & $\begin{array}{l}\text { Adapted MBSR or } \\
\text { MBSR as core }\end{array}$ & $\begin{array}{l}\text { NÄge } \\
\text { (Parents) }\end{array}$ & $\begin{array}{l}\text { NAge } \\
\text { (Children }\end{array}$ & $\begin{array}{l}\text { Percentage of } \\
\text { ASD child }\end{array}$ & Duration & Instrument \\
\hline Bazzano et al. (2013) & $\begin{array}{l}\text { Pre and } \\
\text { Post test } \\
\text { design }\end{array}$ & Core & $\begin{array}{l}66 \text { parents with } \\
\text { ASD \& DD } \\
28 y-71 y r\end{array}$ & $\begin{array}{l}36 \\
\text { children } \\
\text { out of } 61 \\
\text { children }\end{array}$ & $60 \% A S D$ & $\begin{array}{l}8 \times 2 \mathrm{~h} \\
\text { 4h meditation retreat }\end{array}$ & $\begin{array}{l}\text { Mindful Awareness (MAAS) } \\
\text { Stress (PSS10 and ParentSS) } \\
\text { Psychological Well-Being (PWB) } \\
\text { Self-Compassion (SCS) } \\
\text { Self-Rated Physical Health }\end{array}$ \\
\hline $\begin{array}{l}\text { Lewallen \& Neece } \\
\text { (2015) }\end{array}$ & $\begin{array}{l}\text { Pre and } \\
\text { Post test } \\
\text { design }\end{array}$ & Core & $\begin{array}{l}24 \text { mothers of } \\
\text { children with } \\
\text { ASD \& DD }\end{array}$ & $2.5-5 y r$ & $83.3 \% \mathrm{ASD}$ & $\begin{array}{l}8 \times 2 \mathrm{~h} \\
\text { 6h meditation retreat }\end{array}$ & $\begin{array}{l}\text { Parenting Relationship Questionnaire } \\
\text { (PRQ) } \\
\text { Social Skills Improvement System (SSIS) }\end{array}$ \\
\hline Dykens et al. (2014) & RCT & Core & $\begin{array}{l}243 \text { mothers of } \\
\text { children with } \\
\text { ASD \& DD } \\
23-76 y\end{array}$ & $2-54 y \Gamma$ & & $6 \times 1.5 h$ & $\begin{array}{l}\text { Life Satisfaction Scale, } \\
\text { Psuchological Well-Being } \\
\text { Parental Stress Index } \\
\text { BDI } \\
\text { BSI }\end{array}$ \\
\hline Neece et al. (2013 a) & $\mathrm{RCT}$ & Core & $\begin{array}{l}46 \text { parents of } \\
\text { children with } \\
\text { ASD \& DD }\end{array}$ & $2.5-5 y r$ & $84.8 \%$ ASD & $\begin{array}{l}8 \times 2 \mathrm{~h} \\
\text { 6h meditation retreat }\end{array}$ & $\begin{array}{l}\text { Parenting Stress Index-Short Form } \\
\text { Family Impact Questionnaire } \\
\text { Center for Epidemiologic Studies } \\
\text { Depression Scale } \\
\text { Satisfaction with Life Scale } \\
\text { Child behaviour checklist for ages 1.5-5 } \\
\text { Subjective Units of Distress Scale }\end{array}$ \\
\hline Roberts et al. (2015) & $\begin{array}{l}\text { Clinical } \\
\text { Trial }\end{array}$ & Core & $\begin{array}{l}43 \text { parents of } \\
\text { children with }\end{array}$ & $2.5-5 y r$ & $84.8 \%$ ASD & $\begin{array}{l}8 \times 2 h \\
\text { Gh meditation retreat }\end{array}$ & FFMQ \\
\hline $\begin{array}{l}\text { Rojas-Torres et al. } \\
\text { (2021) }\end{array}$ & $\begin{array}{l}\text { Non- } \\
\text { randomise } \\
\text { d } \\
\text { Clinical }\end{array}$ & Core & $\begin{array}{l}10 \text { parents of } \\
\text { children with } \\
\text { ASD } \\
\text { Age range : } 37 \text {. }\end{array}$ & $3-10 y$ & $100 \%$ ASD & $\begin{array}{l}8 \text { week, } 90 \mathrm{~min} \text { ( } 1 \text { session } \\
\text { per week) }\end{array}$ & $\begin{array}{l}\text { Mindful Attention Awareness Scale ( } \\
\text { MAAS) } \\
\text { Depression, } \\
\text { Anxiety and Stress Scale (DASS) }\end{array}$ \\
\hline Weitlauf et al. (2020) & $\begin{array}{l}\text { Randomiz } \\
\text { ed Control } \\
\text { Trial } \\
\text { (RCT) }\end{array}$ & Core & $\begin{array}{l}\text { Glparents of } \\
\text { children with } \\
\text { ASD }\end{array}$ & $\begin{array}{l}61 \\
\text { less than } \\
36 \\
\text { months }\end{array}$ & $100 \%$ ASD & & $\begin{array}{l}\text { Parenting Stress Index (PSI), } \\
\text { Center for Epidemiologic Studies } \\
\text { Depression Scale } \\
\text { Beck Anxiety Inventory } \\
\text { Satisfaction With Life Scale } \\
\text { Five Facet } \\
\text { Mindfulness Questionnaire } \\
\text { Child Behavior Checklist } \\
\text { The Vineland Adaptive Behavior } \\
\text { Scales-Second Edition } \\
\text { The Autism Diagnostic Observation } \\
\text { Schedule. }\end{array}$ \\
\hline
\end{tabular}

\section{Research Question 2: Treatment Outcome}

MBSR was initiated by Kabat Zinn in the field of medical to reduce stress and pain symptoms among cancer patients. Later, MBSR had established to become a proven program to reduce stress and enhance mental health in many other settings. This systematic literature review manages to spot the outcomes of MBSR among parents of children with ASD, a population who highly acclaimed to undergone major stress, depression and poor wellbeing. Table 2 summarizes the outcome of the studies. 


\section{MBSR and Stress, Depression and Anxiety}

Out of 9 studies that being sorted, 7 studies documented significant decrease in parental stress (Rojas-Torres et al., 2021; Weitlauf et al., 2020; Dykens et al., 2014; Neece et al., 2013; Neece et al., 2018; Lewallen \& Neece, 2015) and perceived stress (Bazzano et al., 2013) after undergoing MBSR treatment. On top of it, Weitlauf et al., (2020) reports that MBSR plus parent implemented Early Start Denver Model (P-ESDM) shown greater improvement in parental distress and parental child dysfunctional interaction compared to the control group who only receives P-ESDM. Dykens et al (2014) did research on notably highest number of parent of children with ASD sample confirms that MBSR prove to maintain the reduction in parental stress post 6 months follow up. While Neece et al (2018) argues that MBSR had benefited both testing group an did not differ by ethnic status. Bazzano et al (2013) extended the testing of stress level into 2 constructs which are parental stress and perceived stress and reported MBSR gave a profound result on both variables. While three studies had tested the effectiveness of MBSR on both anxiety and depression (Rojas-Torres et al., 2021; Weitlauf et al., 2020; Dykens et al., 2014) while two more studies only focus on depression alone (Neece et al., 2013; Neece et al., 2018). All 5 studies reported that compared to baseline, there was a significant decrease in both Anxiety and Depression level post treatment.

\section{MBSR and Child Behaviour}

Four studies measured child behaviour (Hadley et al., 2020; Neece et al., 2013; Neece et al., 2018; Lewallen \& Neece, 2015). These studies reported significant reduction post intervention in problematic behaviour (Hadley et al., 2020) and improvement in positive adaptive behaviour (Neece et al., 2013). Interestingly, Neece et al (2018) reported there was a significant effect post treatment on parent reported child attention problem. Finally, Hadley et al. (2020) infers that there were a difference of $21 \%$ between pre-test and post test score on parent reported child internalizing

MBSR and Mindfulness

FFMQ and MAAS have been used equally in two studies while BMPS in one study. However all five mindfulness questionnaires reported improved mindfulness within parents of children with ASD post MBSR intervention (Rojas-Torres et al., 2021; Hadley et al., 2020; Weitlauf et al., 2020; Roberts et al., 2015; Bazzano et al., 2013). Hadley et al (2020) summarized that mindfulness plays a key role in changing the perception of parents towards their child's internalization problems which includes depressive, anxiety disorder, somatic complaints, and withdrawal. Rojas-Torres et al (2021) confirms that there is a significant improvement in giving attention and living in present within parents as a result of MBSR intervention.

\section{MBSR and Life Satisfaction}

Life satisfaction is the least variable that being documented and tested. Only 3 studies have explored the relationship between MBSR and life satisfaction (Rojas-Torres et al., 2021; Neece et al., 2013; Neece, et al., 2018). Neece, et al (2018) reported significant improvement on life satisfaction among parents of children with ASD. Interestingly, Rojas Torres et al. (2021) infers that no changes found post MBSR intervention particularly in this domain. 


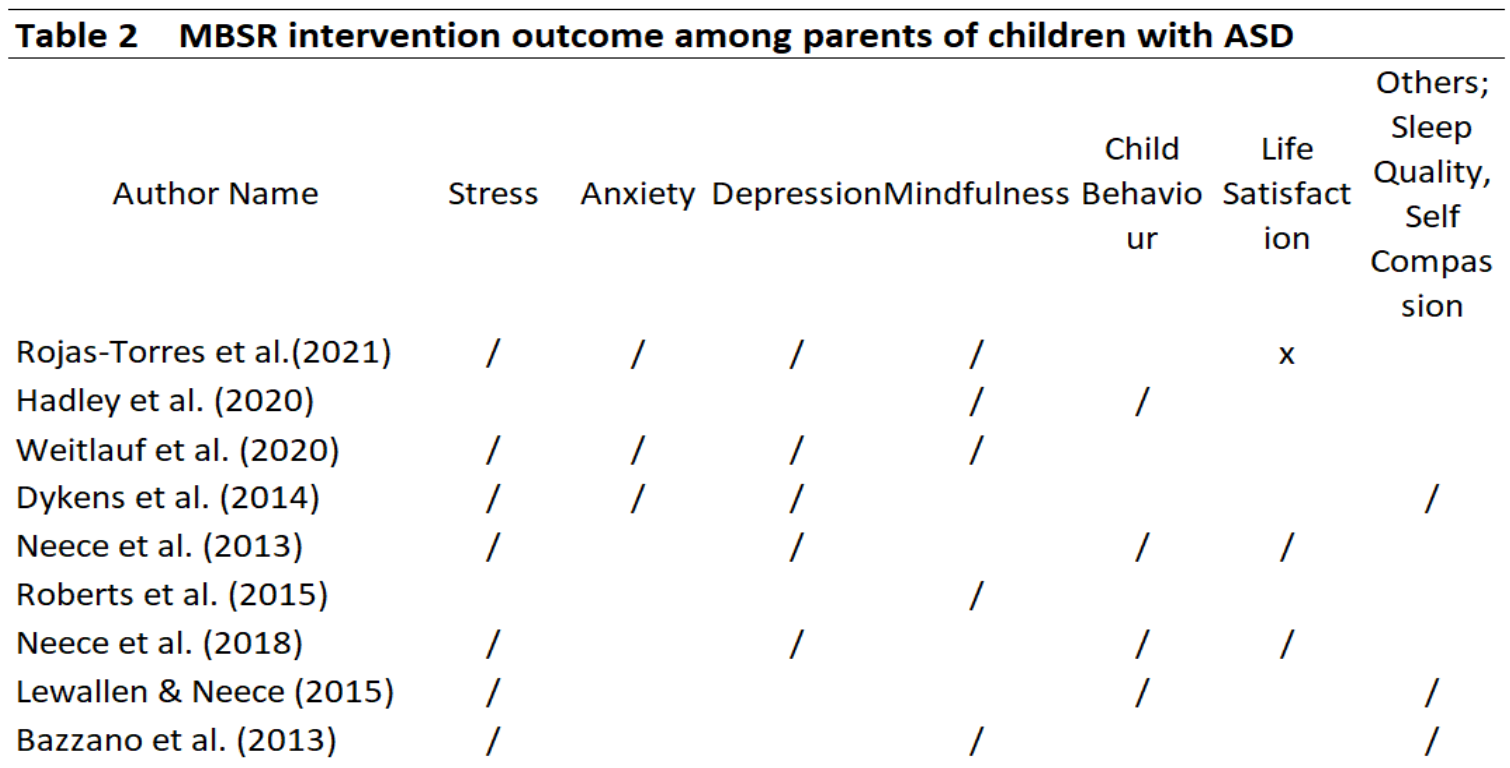

\section{Discussion}

This systematic literature review summarizes the current evidence base for MBSR interventions among parents of children with ASD. Data from nine studies infers how effective MBSR therapies as key intervention on improving parents' mental health and overall wellbeing. This includes parental stress, mindfulness, anxiety, depression, child behaviour and life satisfaction. A small number of studies also had assessed sleep quality, self-compassion, and overall wellbeing. The delivered MBSR framework follows standard structure which is 8 weeks of 2 hours session each while two studies had modified the length of session (Dykens et al., 2014; Rojas-Torres et al., 2021) but still able to share the almost the equal positive changes in parents of children with ASD. This statement is in synch with Osborn et al. (2020), who claims MBSR is potential to have the same benefit regardless of the length of session. Overall, all studies had shows significant changes in parents of children with ASD post treatment.

However there are some notable limitation of this study that need to be highlighted when examining the result of the study. Most of the studies documented a lack of big sample for testing (Rojas-Torres et al., 2021; Neece et al., 2013; Neece et al., 2018) which inhibited the generalization of the results. Some studies suggested to have an active control group in order to enhance their findings (Hadley et al., 2020; Dykens et al., 2014; Neece et al., 2013; Lewallen \& Neece, 2015).The MBSR treatment outcome only embody certain variable but did not include notable variable as per previous studies such as parents' quality of life, marital dysfunction and extended child behaviours. Other than that, out of 9 studies only one study had list down the overview of the program structure which explains better the framework of this approach. Failure to comprehend the framework in the studies inhibit the comparison of structure with other studies.

Notwithstanding these limitations, the present systematic review is the first to examine the treatment outcome of MBSR among parents of children with ASD and can provide some preliminary evidence on the effectiveness of this therapy in relation to parents of children with ASD. Despite its limitations, this review supports an appreciation that this population 
may experience benefit through this therapy as it highlights the factors that have been identified within the existing literature which could improve or impede this intervention. Findings from this study may help the development of future interventions which can be a great influence in health care settings, policy and funding allocations. Future studies should focus more on evident base studies mainly on clinical trials and also cultural differences and acceptance towards this therapy.

\section{References}

American Psychiatric Association. (2013). Diagnostic and statistical manual of mental disorders(5th. Ed.). Washington, DC: APA.

Bazzano, A., Wolfe, C., Zylowska, L., Wang, S., Schuster, E., Barrett, C., \& Lehrer, D. (2015). Mindfulness based stress reduction (MBSR) for parents and caregivers of individuals with developmental disabilities: A community-based approach. Journal of Child and Family Studies, 24(2), 298-308.

Brockman, M., Hussain, K., Sanchez, B., \& Turns, B. (2015) Managing Child Behavior Problems in Children With Autism Spectrum Disorders: Utilizing Structural and Solution Focused Therapy With Primary Caregivers. The American Journal of Family Therapy, 44(1), 1-10.

Cachia, R. L., Anderson, A., \& Moore, D. W. (2016). Mindfulness, stress and well-being in parents of children with Autism Spectrum Disorder: A Systematic Review. Journal of Child and Family Studies, 25(1), 1 - 14. https://doi.org/10.1007/s10826-015-0193-8

Dabrowska, A., \& Pisula, E. (2010). Parenting stress and coping styles in mothers and fathers of pre-school children with autism and Down syndrome. Journal of intellectual disability research: JIDR, 54(3), 266-280. https://doi.org/10.1111/j.1365-2788.2010.01258.x

Dardas, L. A., \& Ahmad, M. M. (2013). Coping Strategies as Mediators and Moderators between Stress and Quality of Life among Parents of Children with Autistic Disorder. Stress and Health, 31(1), 5-12. doi:10.1002/smi.2513

Drmic, I. E., Szatmari, P., \& Volkmar, F. (2018). Life Course Health Development in Autism Spectrum Disorders. In N. Halfon, C. B. Forrest, R. M. Lerner, \& E. M. Faustman (Eds.), Handbook of Life Course Health Development (pp. 237-274). Cham: Springer International Publishing.

Dumas, J. E., Wolf, L. C., Fisman, S. N., \& Culligan, A. (1991). Parenting stress, child behavior problems, and dysphoria in parents of children with autism, down syndrome, behavior disorders, and normal development. Exceptionality, 2(2), 97-110. doi:10.1080/09362839109524770

Dykens, E. M., Fisher, M. H., Taylor, J. L., Lambert, W., \& Miodrag, N. (2014). Reducing distress in mothers of children with autism and other disabilities: a randomized trial. Pediatrics, 134(2), e454-e463. https://doi.org/10.1542/peds.2013-3164

Hartley, S. L., Barker, E. T., Baker, J. K., Seltzer, M. M., \& Greenberg, J. S. (2012). Marital satisfaction and life circumstances of grown children with autism across 7 years. Journal of family psychology : JFP : journal of the Division of Family Psychology of the American Psychological Association (Division 43), 26(5), 688-697. https://doi.org/10. 1037/a0029354

Hayes, S. A., \& Watson, S. L. (2013). The impact of parenting stress: a meta-analysis of studies comparing the experience of parenting stress in parents of children with and without autism spectrum disorder. Journal of autism and developmental disorders, 43(3), 629642. 
Hadley A. M., Sanner, C. M., \& Neece, C. L. (2020). Effects of MBSR Parent Intervention on Internalizing Problems in Children: ASD Status as a Moderator. Journal of Mental Health Research in Intellectual Disabilities, 13(4), 343-363.

Helps, S. (2016). Systemic psychotherapy with families where someone has an autism spectrum condition. NeuroRehabilitation, 38(3), 223-230.doi:10.3233/NRE-161314

Ilias, K., Cornish, K., Park, M. S.-A., Toran, H., \& Golden, K. J. (2019). Risk and Resilience Among Mothers and Fathers of Primary School Age Children With ASD in Malaysia: A Qualitative Constructive Grounded Theory Approach. 9(2275), 1-20. doi:10.3389/fpsyg.2018.02275

Kabat-Zinn, J. (2003). Mindfulness-Based Interventions in Context: Past, Present, and Future. Clinical Psychology: Science and Practice, 10(2), 144-156. doi:10.1093/clipsy.bpg016

Kamaralzaman, S., Toran, H., Mohamed, S., and Abdullah, N. B. (2018). The economic burden of families with autism spectrum disorders (ASD) children in Malaysia. J. ICSAR, 2, 7177.

Karst, J. S., \& Van Hecke, A. V. (2012). Parent and family impact of autism spectrum disorders: A review and proposed model for intervention evaluation. Clinical Child and Family Psychology Review, 15(3), 247-277.

Kord, N., \& Bazzazian, S. (2020). The effectiveness of the resiliency training on the perceived stress and coping strategies of the mothers of the children with autism. Archives of Psychiatry and Psychotherapy 4: 22-31.

Kuhlthau, K., Payakachat, N., Delahaye, J., Hurson, J., Pyne, J. M., Kovacs, E., \& Tilford, J. M. (2014). Quality of life for parents of children with autism spectrum disorders. Research in Autism Spectrum Disorders, 8(10), 1339-1350. doi:https://doi.org/10.1016/j.rasd .2014.07.002

Lewallen, A. C., \& Neece, C. L. (2015). Improved social skills in children with developmental delays after parent participation in MBSR: The role of parent-child relational factors. Journal of Child and Family Studies, 24(10), 3117-3129. doi:10.1007/s10826-015-01168

Liberati, A., Altman, D. G., Tetzlaff, J., Mulrow, C., Gøtzsche, P. C., loannidis, J. P., \& Moher, D. (2009). The PRISMA statement for reporting systematic reviews and meta-analyses of studies that evaluate health care interventions: explanation and elaboration. Journal of clinical epidemiology, 62(10), e1-e34.

Lindly, O. J., Chavez, A. E., \& Zuckerman, K. E. (2016). Unmet health services need among US children with developmental disabilities: Associations with family impact and child functioning. Journal of Developmental and Behavioral Pediatrics, 37(9), 712-723.

Millstein, A. R., Lindly J.O., Luverto. M.C., Perez K.G., Schwartz N.G., Kuhlthau.K., Park.R.E. (2020). An Exploration of Health Behaviors in a Mind-Body Resilience Intervention for Parents of Children with Developmental Disabilities. Journal of Developmental \& Behavioral Pediatrics 41(6) : 480-485.

Neece, C. L. (2013). Mindfulness-Based Stress Reduction for Parents of Young Children with Developmental Delays: Implications for Parental Mental Health and Child Behavior Problems. Journal of Applied Research in Intellectual Disabilities, 27(2), 174-186. doi:10.1111/jar.12064

Neece, C. L., Chan, N., Klein, K., Roberts, L., \& Fenning, R. M. (2018). Mindfulness-Based Stress Reduction for Parents of Children with Developmental Delays: Understanding the Experiences of Latino Families. Mindfulness, 10(6), 1017-1030. https://doi.org/ $10.1007 / \mathrm{s} 12671-018-1011-3$ 
Osborn, R., Dorstyn, D., Roberts, L., \& Kneebone, I. (2021). Mindfulness therapies for improving mental health in parents of children with a developmental disability: a systematic review. Journal of Developmental and Physical Disabilities, 33(3), 373-389.

Pisula, E. \& Porębowicz-Do"rsmann A (2017) Family functioning, parenting stress and quality of life in mothers and fathers of Polish children with high functioning autism or Asperger syndrome. PLoS ONE 12(10), 1-19. https://doi.org/10.1371/journal. pone.0186536

Roberts, L. R., \& Neece, C. L. (2015). Feasibility of mindfulness-based stress reduction intervention for parents of children with develop[1]mental delays. Issues in Mental Health Nursing, 36(8), 592-602.

Rojas-Torres, L. P., Alonso-Esteban, Y., López-Ramón, M. F., \& Alcantud-Marín, F. (2021). Mindfulness-Based Stress Reduction (MBSR) and Self Compassion (SC) Training for Parents of Children with Autism Spectrum Disorders: A Pilot Trial in Community Services in Spain. Children, 8(5), 316- 334.

Siah, P. C., \& Tan, S. H. (2016). Relationships between sense of coherence, coping strategies and quality of life of parents of children with autism in Malaysia: a case study among chinese parents. Disability, CBR \& Inclusive Development, 27(1), 78-91.

Vasilopoulou, E., \& Nisbet, J. (2016). The quality of life of parents of children with autism spectrum disorder: A systematic review. Research in Autism Spectrum Disorders, 23, 36-49.

Weitlauf, A. S., Broderick, N., Stainbrook, J. A., Taylor, J. L., Herrington, C. G., Nicholson, A. G., Santulli, M., Dykens, E. M., Juárez, A. P., \& Warren, Z. E. (2020). Mindfulness-Based Stress Reduction for Parents Implementing Early Intervention for Autism: An RCT. Pediatrics, 145(Suppl 1), S81-S92. https://doi.org/10.1542/peds.2019-1895K

Zarbo, C., Compare, A., Grossi, E., \& Melli, S. (2016). Psychological Interventions to Reduce Distress and Improve Quality of Life in Families with Autistic Children. In. Compare.A., Elia.C., Simonelli.G.A. \& Cattafi.F (pnyt.). Psychological Distress pp. 115-127. Bergamo: Nova Science Publisher 